\title{
Carbon Nanotubes as Suitable Electrochemical Platforms for Metalloprotein Sensors and Genosensors
}

\author{
M. Pacios ${ }^{1}$, I. Martín-Fernández², R. Villa², P. Godignon², \\ M. Del Valle ${ }^{1}$ J. Bartrolí1 ${ }^{1}$ and M.J. Esplandiu ${ }^{3}$ \\ ${ }^{1}$ Grup de Sensors i Biosensors, Departament de Química, Facultat de Ciències, \\ Edifici C-Nord, Universitat Autònoma de Barcelona, Barcelona, \\ ${ }^{2}$ Centro Nacional de Microelectrónica (CSIC), Campus UAB, Barcelona, \\ ${ }^{3}$ Centro de Investigación en Nanociencia y Nanotecnología, \\ CIN2 (CSIC-ICN), Campus UAB, Barcelona, \\ Spain
}

\section{Introduction}

In the last decade we have been witnesses of the immense scientific production concerning cabon nanotubes (CNTs). Apart from their exceptional electrical and mechanical properties, CNTs provide interesting electrochemical properties which arise from the combination of their good electrical conductivity, their nanometer size, high aspect ratio, structure, electrochemical stability and surface chemistry (McCreery, 2008; Esplandiu, 2009). A vast number of papers have claimed electrocatalytical properties on CNTs which were correlated with enhanced electron transfer rates, increased signal currents and decreased overpotentials, (Wang, 2005; Gooding, 2005; Banks, 2006). However the fundamentals of such special electroactivity of CNTs are still in debate. In some cases, it has been observed an enhanced electrochemical response of CNT to particular redox systems which was explained by the presence of some metal impurities from the catalyst involved in the CNT growth (Jones, 2007). On the other side, it is well known that edge defects and oxygen functionalities at the surface play a major role in the electrochemical behavior of graphitic materials (McCreery, 2008). Under this context, there has been a large amount of work that has explained the special electrocatalytical properties of the CNTs linked to that of Highly Oriented Pyrolytic Graphite (HOPG). These studies are based on the fact that CNT properties are not so different from HOPG and exhibit similar electrochemical anisotropy. Open ends of the CNT or locations on the tube axis where graphitic sheets terminate (edge defects) exhibit higher electron kinetics (similar to edge-HOPG) whereas CNT walls have lower electron transfer kinetics (similar to basal HOPG) (Moore, 2004; Banks, 2005). However such issue should not lead us to completely disregard the intrinsic electrochemical activity of the CNT walls (Dumitrescu, 2009; Salinas-Torres, 2011). Summed up to all these aspects, CNTs exhibit high specific surface area not only for the electron transfer process itself but also for covalent or non- 
covalent (bio)molecule fucntionalization (Katz, 2004; Wang, 2005; Tasis, 2006). Moreover, CNTs represent a versatile material which can be tailored in different geometrical electrode arrangements for exploiting their more electroactive sites (Esplandiu, 2009). All these ingredients make CNT systems ideal candidates for amplified signal transduction in the (bio)electrochemical sensing field.

Accordingly, an overwhelming number of electrochemical biosensing systems on CNT electrodes have been studied such as enzymatic/redox protein biosensors, genosensors or immunosensors which have boosted the potentialities of CNTs as suitable platforms for transducing biorecognition events into useful electroanalytical signals.

\subsection{Enzymatic/protein CNT sensors}

Electrochemical enzymatic/protein sensors are based on the immobilization of redox proteins on an electrode. In most of the cases the electrode itself can replace physiological partners or natural electron acceptors, providing the driving force to energize the reaction and a sensor to measure the response. For instance, in the case of glucose oxidase (GOx), which catalyses the reaction glucose $+\mathrm{O}_{2} \rightarrow$ glucolactone $+\mathrm{H}_{2} \mathrm{O}_{2}$, with oxygen acting as its natural electron acceptor to regenerate the enzyme, the electrode can take the role of its natural partner oxygen (Patolksy, 2004; Cai, 2004). Consequently the main goals when preparing redox enzymatic sensors are to preserve the biomolecule activity when immobilized on the electrode and also to guarantee a good electrochemical communication between the redox active center and the electrode to facilitate the enzyme turnover (Guiseppi-Elie, 2002; Wang, 2005; Gooding, 2005; Kim, 2007; Katz, 2004). However, such goals are rather difficult to achieve since proteins, when adsorbed on electrode surfaces, undergo denaturation with the consequent loss of their electrochemical activity. Moreover, some enzymes contain the redox active centre buried deep inside the protein and it is necessary to utilize mediators to accomplish an electrochemical response (Cai, 2004; Willner, 2004). Therefore, the nature and properties of the surface of the electrode are crucial in dictating how the electron exchange takes place. In this sense, not only the electrochemical reactivity of the surface is important, but also the disposition of the protein and its redox active center on the surface. This in turn strongly depends on the electrode charge density, its hidrophilicity/hidrophobicity or the strength of the interaction.

All the aspects mentioned above have to be considered and optimized in order to get a detectable, reliable and quantifiable electroanalytical response of the enzymatic process.

Under this context, CNTs have been highly appreciated as suitable platforms for anchoring redox enzymes/protein without the loss of the bioactivity and also for allowing a more direct electron transfer with the protein electroactive center and thus avoiding the use of redox mediators (Willner, 2004; Cai, 2004; Esplandiu, 2009). For instance, GOx represents a very interesting model system which is known to have the redox active center (flavin adenine dinucleotide, FAD) deep inside the peptide environment (Willner, 2005; Liu, 2005). Many nanotube modified electrodes have shown to exhibit direct electron transfer to glucose oxidase and at the same time preserving its bioactivity. The direct electron transfer was attributed to the nanotubes being able to penetrate the protein and get close to the FAD center due to their nanometric size (Guiseppi-Elie, 2002).

Additionally CNTs can play an amplification role for the recognition and transduction events due to their high specific area that allows the analyte to be accumulated (Wang, 2005). Moreover, CNTs have been also shown to promote a dramatic decrease in the 
overpotential of some important species $\left(\mathrm{H}_{2} \mathrm{O}_{2}, \mathrm{NADH}\right)$ involved in electrocatalytic enzymatic reactions such as oxidases or dehydrogenases (Wang, 2003; Wang 2005, Rubianes, 2006). For instance, the bioactivity of a CNT electrode modified with GOx can be monitored by the reduction or oxidation of $\mathrm{H}_{2} \mathrm{O}_{2}$. The detection of $\mathrm{H}_{2} \mathrm{O}_{2}$ has been carried out at such low overpotentials that interferences with other analytes can be minimized (Wang, 2003; Rubianes, 2006).

Direct electron transfer has also been observed with many metalloproteins such as cytochrome C, horseradish peroxidase, microperoxidase (MP-11), myoglobin, hemoglobin, catalase, azurin, etc, immobilized on different CNT modified electrodes (Gooding, 2003; Yu, 2003; Zhao, 2006; Zhao, 2006a; Zhang, 2007; Li, 2006; Zhang, 2004; Esplandiu, 2009a; Pacios, 2009. Palangsuntikul, 2010; Kumar, 2011). Myoglobin (Mb), a small water soluble protein involved in the binding and storage of oxygen in cells, has been the subject of numerous studies in redox protein sensors. This protein has a hemin core capable of redox activity and exhibits a catalytical response in presence of some analytes such as oxygen, $\mathrm{H}_{2} \mathrm{O}_{2}$ or $\mathrm{NO}$ (Zhang, 2004; Li, 2006; Zhao, 2006; Pacios, 2009; Esplandiu, 2009a). It is generally difficult for $\mathrm{Mb}$ to transfer electrons to a conventional electrode, but CNT electrodes have once again demonstrated their performance as suitable electrode material for such protein and have promoted applications as potential (bio)sensors of oxygen or hydrogen peroxide or as reduction catalyst in batteries and fuel cell systems. Taking advantage of the CNT benefits as electrode substrates for (bio)sensing, some groups have investigated the physisorbed $\mathrm{Mb}$ response on randomly dispersed carbon nanotube modified substrates (Zhang, 2004; Li, 2006; Zhao, 2006). In all cases, direct electron exchange between $\mathrm{Mb}$ and $\mathrm{CNT}$ was observed in a quasi-reversible heme $\mathrm{Fe}(\mathrm{III}) / \mathrm{Fe}(\mathrm{II})$ voltammetry response. However, it has been scarcely exploited the use of forest carbon nanotubes, which are expected to be more suitable platforms for the protein anchorage and for the electron transfer kinetics (due to the high density of fast electron exchange CNT edges facing the redox biomolecules) (Yu, 2003; Esplandiu, 2009).

\subsection{Genosensors}

A genosensor consists in a substrate modified with specific oligonucleotides (probe DNA) that can detect complementary DNA sequences (target DNA) through hybridization. The determination of nucleic acid sequences from humans, animals, bacteria and viruses constitute the starting point to solve different problems such as food and water contamination caused by microorganisms, detection of generic disorders, tisssue matching, forensic applications, etc. A growing number of research groups in the field of DNA sensors have opted to use electrical and electrochemical detection strategies in an effort to avoid some of the problems associated with the fluorescence protocols (Drummond, 2003, Bonanni, 2009; Bonanni, 2010; Bonanni, 2010a). The electrochemical biorecognition represents a practical approach in which the DNA probe is immobilized on an electrical active surface and the hybridization process is measured as a change in electrical parameters (e.g. current, potential, conductance, impedance, capacitance). Again, the use of CNTs in electrochemical DNA biosensors is quite promising for the reasons given before: CNTs constitute novel platforms for DNA immobilization with important electrochemical transducing properties and high specific surface area which can increase not only the attached DNA amount but also concentrate a great number of enzymes or electroactive nanoparticles to amplify DNA hybridization (Wang, 2003; Wang, 2004; Wang, 2004a; Wang, 
2005; He, 2006; Kim, 2007,). For instance it has been observed in some studies an enhanced guanine signal which was attributed to a CNT-induced interfacial accumulation of the analyte (due to its large surface area/volume ratio). Other groups have demonstrated the advantages of CNT edges for increasing the electron transfer rates of guanine and adenine bases by measuring adsorbed DNA on bamboo like multiwalled carbon nanotubes (these ones having higher density of edge planes as compared to hollow type multiwalled CNTs) (Heng, 2005).

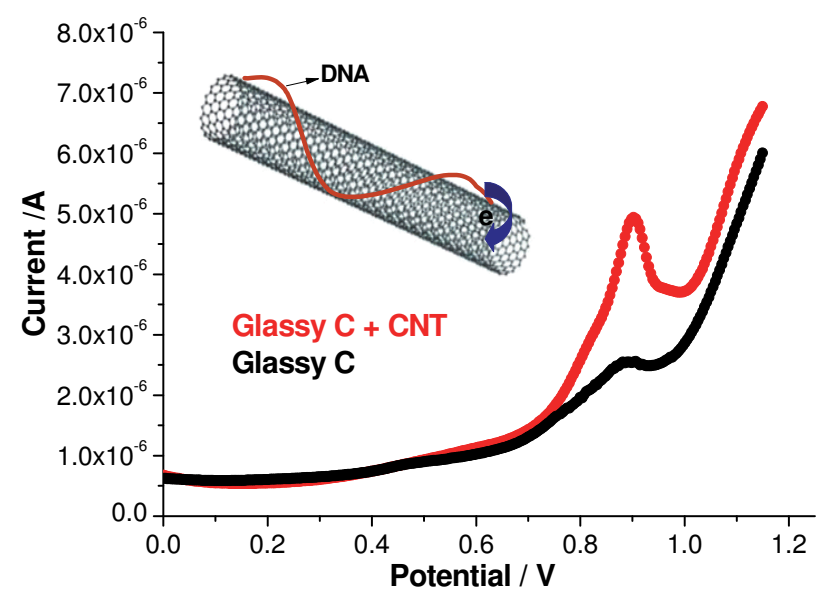

Fig. 1. Differential Pulse Voltammetry (DPV) of a glassy carbon/CNT electrode with physisorbed Polyguanine (Poly-G) (in red) and of a glassy carbon electrode with physisorbed Poly-G (in black). The peak corresponds to the direct oxidation of guanine. Note the enhanced signal of the Poly-G oxidation when it is adsorbed on the CNT support. That is due to the high surface area of CNTs which allow more analyte loading on their surface.

There are many strategies to detect hybridization events; they can be grouped mainly in those based on labeling target DNA or those using a label free approach (Drummond, 2003; Bonanni, 2010a). In the latter case, the more simple strategy is based on the direct oxidation of the DNA bases physisorbed on the CNT material. Although label-free DNA detection protocols are quite desirable since they greatly simplify DNA hybridization assays, such detection schemes can suffer from some drawbacks. On one side, the physisorption of DNA is a multisite attachment which reduces the flexibility of the biomolecule on the electrode support. In the case of hydrophobic electrodes such as CNTs, DNA physisorbs with the bases (apolar region of the molecule) in close contact with the hydrophobic walls whereas the phosphate backbone faces the solution (Carot, 2010). Such orientation of the adsorbed DNA and the reduced flexibility of the adsorbed DNA can decrease the efficiency of the hybridization event. Albeit the direct oxidation does not need the additional use of redox labellings, the process itself also presents the difficulties of the high oxidation potentials at which significant background currents are present (Wang, 2003; Wang, 2004). Among the DNA bases, guanine is the one which exhibits the lower electrochemical overpotential for oxidation, though still remains relative high (close to $1 \mathrm{~V}$ ). CNTs can help to increase the 
CNT signal response from the background noise due to surface area effects (more loading of the probe and target species as observed in Figure 1)(Wang, 2003; Wang, 2004; He, 2006). Despite the potential capacity of CNTs to overcome some of these issues, the strategy is not so practical since DNA oxidation is an irreversible process that impedes the consequent use of the electrode for additional studies (Drummond, 2003) and is limited by the content of DNA bases with low oxidation overpotentials such as guanine. In many cases it is also necessary to manipulate the DNA probe in order to avoid interferences of the guanine oxidation from the probe when monitoring the DNA target (He, 2006). That is why the guanine in single-stranded DNA probe is often replaced by inosine. With that strategy one can reduce the background signal interference derived from single strand DNA probe and consequently increase the hybridization signal derived from double-stranded DNA helix (He, 2006).

There are also many studies that rely on the DNA base oxidation by using flexible probe DNA analyte covalently anchored by a single point linkage (Drummond, 2003; Koehne, 2004). That approach can be achieved by using carbodiimide chemistry which allows establishing an amide bond between - $\mathrm{COOH}$ functional groups of the $\mathrm{CNT}$ and amine terminated oligonucleotide probes. Such strategy is supposed to increase the hybridization efficiency but requires base oxidation mediators such as ruthenium complexes that mediate the redox process between the guanine base and the electrode. The need of a mediator is due to the fact that in a single point DNA attachment, the guanine bases are not in close contact with the CNT surface like in the multisite physiadsorbed oligonucleotides and consequently the direct base oxidation is not achievable. Again this strategy suffers from the irreversibility of the redox process (Figure 2).
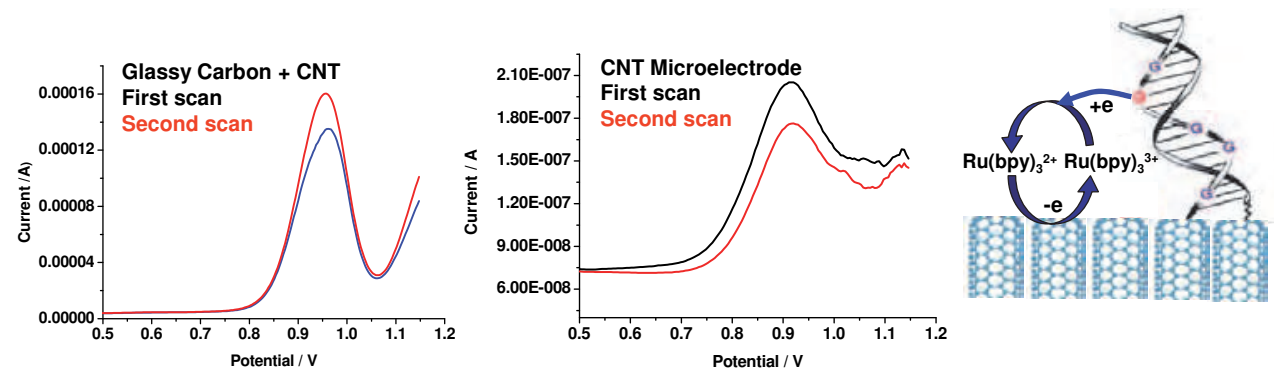

Fig. 2. DPV profiles of covalently attached Poly-G on CNT/glassy carbon electrodes and on CNT microelectrodes. In this case a redox indicator must be used $\left(\mathrm{Ru}(\mathrm{byp}) 3^{2+/ 3+}\right)$ which oxidizes guanine and then exchanges the electron with the electrode. The first scan of the DPV profiles exhibits an enhanced oxidation signal due to the effect of the guanine oxidation but due to the redox irreversibility of guanine there is no contribution of the DNA base in the second scan and consequently the oxidation signal is lower than in the first scan.

Regarding the labelled DNA detection schemes, one common strategy includes the chemical labeling of target DNA sequences with redox active molecules, enzymes, nanoparticles, etc (Fan, 2003; Pividori, 2003; He, 2004a; He, 2006; Bonanni, 2007; Bonanni, 2010). In the case of enzymatic labels bound to the DNA target, the enzyme triggers the catalysis of a redox active reaction under hybridization. For instance by using a horseradish peroxidase-labeled 
DNA target, $\mathrm{H}_{2} \mathrm{O}_{2}$ peroxide is produced which can be detected amperometrically, so the redox reaction of $\mathrm{H}_{2} \mathrm{O}_{2}$ is an indication of the hybridization process. A variation in such approaches involves a three-component "sandwich" assay, in which the redox label is attached to a synthetic sequence specifically designed to bind an overhang portion of the probe and target DNA. All these approaches need an extra chemical labeling step either in the target DNA or in the synthetic oligonucleotide which makes the process more expensive and effortful (Drummond, 2004).

One alternative way that avoids chemical labeling steps is to use redox active reporter molecules that intrinsically associate with the double helix in a non-covalent manner. These reporter molecules can interact with the DNA either by electrostatic interactions or by intercalative means (in such cases DNA has been considered by some authors as a charge mediator) (Drummond, 2004, Gorodetsky, 2008). Some examples of the former molecules are the highy positively charged cobalt and ruthenium complexes (eg. Co(phen) $3^{3+}$, $\left.\mathrm{Ru}\left(\mathrm{NH}_{3}\right)_{6}{ }^{3+}\right)$. These positively charged complexes can strongly interact with the negatively phosphate backbone. As the hydridization process takes place, proportionally more positively charged complexes bind yielding to a higher signal. The other kind of reporter molecules is redox probes that can be specifically intercalated in double strand DNA. An example of these sorts of molecules is the methlylene blue. These molecules have been also used as reporters on perturbations in base stacking.

The approaches with non-covalent and reversible redox reporters are highly sensitive, simple and do not damage the sample which gives the advantage of further use of the sample. Moreover, the redox molecule reporter strategy together with the functionalization and signal amplification capabilities of the CNTs, the powerful electrochemical detection techniques and the possibilities of sensor miniaturization can provide important stimulus to the field of genosensing and diagnosis.

Under the context of the above introduction, in this chapter we would like to highlight some examples of how carbon nanotubes exhibit important capabilities as biosensor transducers. The first example will be related to the role of CNTs in enzymatic sensors, by modifying the CNT platforms with myoglobin $(\mathrm{Mb})$. Although myoglobin is not an enzyme, it can behave as such in presence of certain analytes such as $\mathrm{H}_{2} \mathrm{O}_{2}, \mathrm{O}_{2}$ or NO. Myoglobin also has the active redox center embedded deep in the protein network which makes the direct electron transfer in conventional electrodes difficult. We will demonstrate the suitability of CNT platforms for loading myoglobin without losing its activity and also the potentialities of CNT electrodes for enhancing the direct electrochemistry with the redox active center of the protein. Special emphasis will be put on vertically aligned CNT electrodes. We will demonstrate how all these features can exert a big influence on the sensor capabilites of myoglobin when exposed to specific analytes $\left(\mathrm{O}_{2}\right.$ or $\left.\mathrm{H}_{2} \mathrm{O}_{2}\right)$ which encourage the use of such CNT modified systems in clinical diagnosis or in environmental assays.

The second example will be related to the use of CNTs as platforms for genosensors. In this section we will mainly discuss the use of microelectrode arrays made of vertically aligned CNTs as substrates for chemically anchoring of DNA. We will use the strategy of the highly positively charged redox reporters as indicators of the hybridization process which will be monitored by cyclic voltammetry and by other simple and highly sensitive techniques such as chronocoulometry and impedance spectroscopy. We will show that miniaturization of CNT electrodes results crucial when using impedance measurements for detecting DNA biorecognition with positively charge redox reporters. 


\section{Experimental}

\subsection{Myoglobin modified CNT electrodes}

\subsubsection{Working electrodes}

Different carbon nanotube electrodes were used as working electrodes: vertically aligned CNTs and CNT epoxy composites. The behahvior of the CNT electrodes were compared in different aspects with other electrodes such as graphite epoxy composites, Au coated silicon electrodes and Highly Oriented Pyrolytic Graphite (HOPG, SPI-3 grade, SPI supplies, PA, USA).

The vertically aligned multi-walled carbon nanotubes were grown on silica substrates and were provided by MER Corporation (Tucson, AZ, USA). The thickness of the resulting nanotube film was around $30-40 \mu \mathrm{m}$.

Graphite-expoxy composites were made from graphite powder of 10-20 $\mu \mathrm{m}$ particle size. Carbon nanotube composites were fabricated using multi-walled carbon nanotubes (MWNTs) grown by CVD with lengths between 5-15 $\mu \mathrm{m}$, diameter of $30 \mathrm{~nm}$ and purity of 96-98\% (SES Research, Houston, TX, USA). In both cases, Epotek H77 resin and hardener (both from Epoxy Technology, Billerica, MA, USA) were used for the composite fabrication. Composite electrodes were prepared, following the standard protocol in our laboratories (Pumera, 2006; Pacios, 2008). The composite was prepared by first mixing manually the epoxy resin and the hardener in a 20:3 ratio (w:w), respectively. Then the carbon source was added to the epoxy mixture in a $20 \%$ in weight proportion. The carbon paste was well mixed during one hour and put in the cavity of the plastic body (around $3.5 \mathrm{~mm}$ in depth). Finally the material was cured at $100^{\circ} \mathrm{C}$ for 10 hours. Before each use, the surface electrode was polished with emery paper of different grain grades and then with $0.3 \mu \mathrm{m}$ alumina paper (polishing strips 301044-001, Thermoelectron).

\subsubsection{Electrode modification}

Horse heart myoglobin (Sigma, MA, USA) was dissolved in $0.1 \mathrm{M}$ phosphate buffer solution (PBS, $137 \mathrm{mM} \mathrm{NaCl}, 2.7 \mathrm{mM} \mathrm{KCl}, 10 \mathrm{mM} \mathrm{Na}_{2} \mathrm{HPO}_{4}, 2 \mathrm{mM} \mathrm{KH}_{2} \mathrm{PO}_{4}, \mathrm{pH}=7.4$ ).

For the covalent immobilization of the proteins on carbon electrodes, $N-(-3-$ dimethylaminopropyl)- $N^{\prime}$-ethylcarbodiimide hydrochloride (EDAC, Sigma, MA, USA) was used.

All electrodes were first oxidized by electrochemical pretreatments in order to increase the oxygen moieties for covalent attachment by carbodiimide chemistry. In the case of the vertical aligned $\mathrm{CNT}$, also a heat treatment $\left(\right.$ at $\left.470^{\circ} \mathrm{C}\right)$ in air was performed. Then, the carbon electrodes were immersed in myoglobin solutions in PBS $(3 \mathrm{mg} / \mathrm{ml})$ in presence of EDAC $(3 \mathrm{mg} / \mathrm{ml})$ during 12 hours. Finally, they were thoroughly washed in PBS for one hour and dried with nitrogen.

\subsubsection{Electrochemical behavior and electrocatalytical effects}

The electrocatalytic activity of myoglobin in presence of $\mathrm{H}_{2} \mathrm{O}_{2}$ was studied by using hydrogen peroxide solutions at different concentrations. Such solutions were dearated bubling $\mathrm{N}_{2}$ for at least 15 minutes.

\subsubsection{Instrumentation}

All measurements were performed with the normal three-electrode configuration. A Pt wire was used as counter electrode and an $\mathrm{Ag} / \mathrm{AgCl}$ electrode was acting as reference (in close 
proximity to the working electrode to minimize the ohmic drop). For the electrochemical characterization we have used Cyclic voltammetry from an electrochemical workstation (IME6, Zahner, Germany).

\subsection{DNA modified CNT electrodes \\ 2.2.1 Working electrodes}

The microelectrode array electrode with forest CNTs was fabricated as follows (MartinFernández, 2010). First, a $150 \mathrm{~nm}$ thick Pt layer was patterned by conventional photolithography on silicon wafers that were previously thermally oxidized. A $30 \mathrm{~nm}$ thick titanium layer was deposited by sputtering between $\mathrm{SiO}_{2}$ and $\mathrm{Pt}$ to improve the adherance to the substrate. Then a $15 \mathrm{~nm}$ thick $\mathrm{SiO}_{2}$ layer was deposited by PECVD and after that a $4 \mathrm{~nm} \mathrm{Pt}$ layer was sputtered on top of the $\mathrm{SiO}_{2}$ which would act as the catalyst layer. The $\mathrm{SiO}_{2}$ layer between the two $\mathrm{Pt}$ ones is to avoid the diffusion of $\mathrm{Pt}$ forming the electrode (thick Pt layer) and the catalyst layer. After that, CNT growth was performed in a JetStar 100ST Rapid Thermal CVD from Jipelec in a two step process, the catalyst activation step $\left(800{ }^{\circ} \mathrm{C}, 500 \mathrm{sccm}\right.$ $\mathrm{H}_{2}$ for $5 \mathrm{~min}$ ) and the $\mathrm{CNT}$ growth step $\left(800^{\circ} \mathrm{C}, 1000 \mathrm{sccm} \mathrm{CH}_{4}\right.$ for $\left.5 \mathrm{~min}\right)$. The final fabrication step consited in introducing the devices in a HF based solution to etch the $15 \mathrm{~nm} \mathrm{SiO}$ layer on the contact pads after the wafers had been diced. The final array of microelectrodes consisted in four electrodes of $300 \mu \mathrm{m} \times 300 \mu \mathrm{m}$ size as can be depicted in Fig. 3.

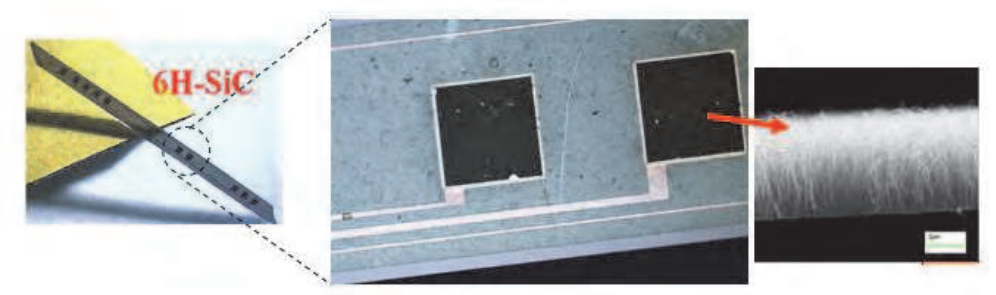

Fig. 3. CNT microelectrode with the zoom of two microelectrode patches of $300 \mu \mathrm{m}$ size each of them. The CNTs were grown by chemical vapor deposition in an upright configuration.

For comparison we also used macroscopic electrodes made of vertically aligned multiwalled carbon nanotubes grown on silica substrates (MER Corporation, Tucson, AZ, USA) and CNT dispersed on glassy carbon electrodes.

\subsubsection{Electrochemical pre-treatment of the working electrodes}

Electrochemical pretreatment was performed for two reasons, one for cleaning the CNTs by oxidizing the amorphous carbon and the other for generating carboxylic moieties for further covalent functionalization. Three electrochemical treatment procedures were performed with different electrolytes (in $0.1 \mathrm{M} \mathrm{HNO}_{3}, 10 \mathrm{sec}, 1 \mathrm{~V}$; in $0.1 \mathrm{M} \mathrm{KCl} 60 \mathrm{sec}, 1.75 \mathrm{~V}$ and in 1 $\mathrm{M} \mathrm{NaOH}, 60 \mathrm{sec}, 1 \mathrm{~V}$ ). Treatments in $\mathrm{NaOH}$ solutions provided the best electrochemical response based on cylic voltammetry measurements $(\mathrm{CV})$ in presence of a redox benchmark $\mathrm{Fe}(\mathrm{CN})_{6}{ }^{3-/ 4}$. Specifically, for such treatment, we observed higher current signal and a decrease in the peak potential difference as indication of the enhancencement of the electrochemical performance (increase of the electrode reversibility). 


\subsubsection{The immobilization of oligonucleotide on electrode}

The immobilization of the DNA was performed by following the carbodiimide chemistry. The $-\mathrm{COOH}$ terminal groups of the $\mathrm{CNTs}$ were activated by immersing in $0.05 \mathrm{M}$ EDAC/0.03M Sulfo-NHS in PBS solution for 15 minutes. These compounds transform the carboxyl group in an amine-reactive ester. After rinsing in PBS, the modified electrode was incubated overnight in $1 \mu \mathrm{M}$ PolyC- $\mathrm{NH}_{2}$ oligonucleotide (20 bases). Then the electrodes were immersed for 15 minutes in $0.05 \%$ SDS + $0.04 \mathrm{M}$ Hydroxylamine solution to remove non-specific adsorption and to deactivate free $-\mathrm{COOH}$ groups.

\subsubsection{Hybridization with DNA target}

The electrode was immersed for other 15 minutes in 0.01 M PEG in PBS to avoid nonspecific adsorption in the consequent hybridization process. After that, the electrodes were incubated for 30 minutes in different concentrations of the complementary strand (from $10^{-10} \mathrm{M}$ to $10^{-6} \mathrm{M}$ in PBS ) of PolyG (20 bases). Negative controls were also made with nocomplementary oligonucleotide (PolyT).

\subsubsection{Instrumentation}

All measurements were performed with same three-electrode configuration mentioned above. For the electrochemical characterization we have used different electrochemical techniques: cyclic voltametry, differential pulse voltammetry, chronocoulometry and impedance spectroscopy.

Cyclic voltammetry and Impedance Spectroscopy were obtained with an electrochemical workstation (IME6, Zahner, Germany). Chronocoulometry were performed in Autolab electrochemical workstation.

The cyclic voltammetry and impedance spectroscopy were performed in presence of the redox reporter $\mathrm{Ru}\left(\mathrm{NH}_{3}\right)_{6}{ }^{3+}$ at a concentration of $1.8 \mathrm{mM}$ in TRIS buffer. The chronocoulometry was performed either in $10 \mathrm{mM}$ TRIS $+10 \mathrm{mM} \mathrm{NaCl}$ or in the same electrolyte with $50 \mu \mathrm{M}$ of $\mathrm{Ru}\left(\mathrm{NH}_{3}\right)_{6}{ }^{3+}$.

\section{Results}

\subsection{Myoglobin modified CNT electrodes}

\subsubsection{Direct electrochemistry of the metalloproteins}

As mentioned in the introduction, one of the main issues in electrochemical enzymatic/protein sensors is to achieve the capability of direct electron transfer between the electroactive biomolecule center and the electrode and to keep at the same time the biomolecule bioactivity. This issue is very important to guarantee efficient applications. In this section we will demonstrate how CNT electrodes facilitate the direct electron transfer with myoglobin by using cyclic voltammetry in deaerated solutions of PBS. Cyclic voltammetry is a useful technique to get fast information on the thermodynamic of processes and on the redox kinetics of heterogeneous electron transfer reactions. It allows a rapid location of redox potentials of the electroactive species and convenient evaluation of the effect of the environment upon the redox process. Fig. 4 shows the cyclic voltammograms for the case of myoglobin covalently immobilized on different carbon substrates: vertically aligned CNTs, CNT epoxy composites and graphite composites. These electrodes exhibit an anodic and cathodic peak corresponding to the direct electron transfer between the hemin core of the myoglobin (Fe(III)/ Fe(II)) and the carbon based electrodes 
(Esplandiu, 2009a). Such electrochemical response is reversible and can be evidenced by the small peak potencial diferences $(\Delta \mathrm{Ep})$ between the anodic and cathodic wave. The smaller the peak separation, the more facile is the electron transfer process.

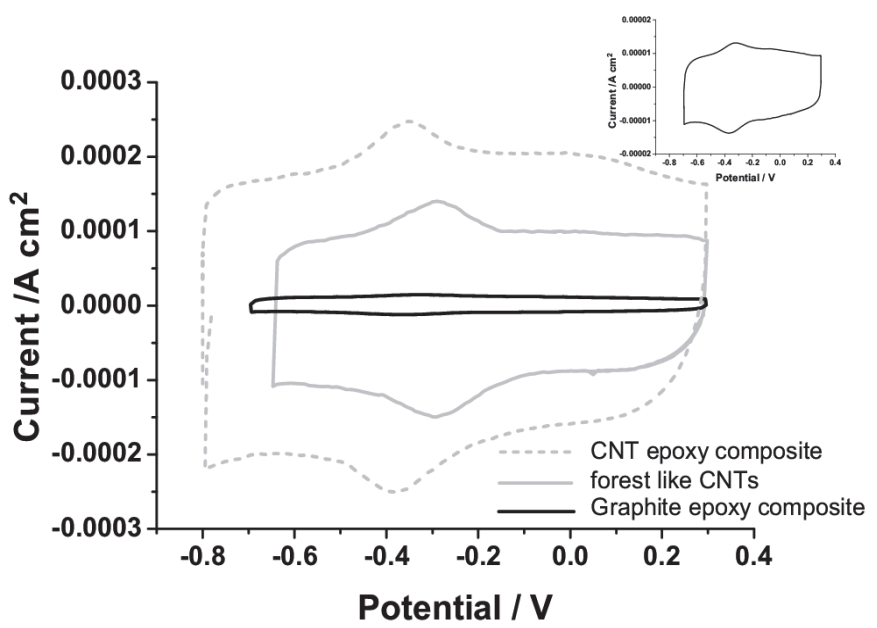

Fig. 4. Cyclic voltammograms for a forest like CNT electrode, CNT and graphite epoxy composite modified with $\mathrm{Mb}$ in deareated PBS solutions at a scan rate of $0.1 \mathrm{~V} / \mathrm{s}$. A zoom of the graphite composite response is also depicted. Reproduced with permission from (Esplandiu, 2009a). Copyright, 2009, IOP Publishing.

We have used the values of $\Delta \mathrm{Ep}$ at $0.1 \mathrm{~V} / \mathrm{s}$ in order to extract the electron transfer rate constants using the Laviron method (Laviron, 1979) (Table 1). From such values one can see that the electrochemical response of Myoglobin on CNT electrodes is improved compared to the case of graphite composites. We have found that forest-like CNTs exhibit the smallest peak separation and highest electron transfer rate constant followed by the CNT and graphite epoxy composites (Esplandiu, 2009a).

\begin{tabular}{llll}
\hline Carbon electrode & $\Delta \mathbf{E p} / \mathbf{~ m V}$ & $\mathbf{k ~ s}^{-1}$ & $\Gamma^{*} \mathbf{r}\left(\mathbf{m o l ~ c m} \mathbf{~ m}^{-2}\right)$ \\
\hline Graphite epoxy composite & $43 \pm 3$ & $3.1 \pm 0.3$ & $6.810^{-11}$ \\
\hline Carbon nanotube epoxy composite & $21 \pm 4$ & $7 \pm 1$ & $8.010^{-10}$ \\
\hline Forest like CNTs & $8 \pm 3$ & $15 \pm 4$ & $3.010^{-10}$ \\
\hline
\end{tabular}

Table 1. Electrochemical parameters of the carbon based electrodes. (Adapted from (Esplandiu, 2009a)

As mentioned in the introduction, edge defects promote high electron transfer rates at the carbon electrode interface and also become the active sites for the covalent attachment. Probably the higher density of edges of the forest CNT electrodes, which are concentrated just at the interface with the electrolyte, could favor a better protein wiring at the CNT substrate and promote the electron exchange. In the case of the CNT composites, the relatively lower electron transfer rate can be rooted in the more heterogeneous complexity of the porous CNT composite. Protein can be anchored on CNT composites through 
exposed edges on the CNT tips, on defects at the uncoated walls or on defects at insulated polymer coated CNTs. All these characteristics could explain the lower transfer rate as compared with the forest like systems. Although the CNT epoxy composites have lower electron transfer kinetics, they exhibit a higher current signal, which can be due to a higher material porosity providing more surface area for protein immobilization. An estimate of the protein surface coverage $(\Gamma)$ for every electrode can be made from the peak current $\left(\mathrm{I}_{\mathrm{p}}\right)$ as a function of the scan rate by using the relation corresponding to a reversible adsorbate electroactive layer, $i_{p}=9.3910^{5} n^{2} v A \Gamma$. In this relation, $n$ represents the number of exchanged electrons, $v$ is the scan rate, and $A$ is the electroactive surface area which depends on the roughness of the surface. The true surface area and coverage are very hard to evaluate independently, therefore we have reported the protein coverage per unit of geometrical area, i.e Г.A/ $\mathrm{A}_{\text {geom }}=\Gamma$.r. The values obtained are listed in Table 1, and give an indication of the amount of protein deposited in each electrode. As anticipated, the higher $\mathrm{Mb}$ surface coverage on the $\mathrm{CNT}$ composite as compared to the other carbon electrodes is probably due to its larger porosity and roughness degree, which facilitates the immobilization of higher amounts of protein and amplifies the signal response (Esplandiu, 2009a).

\subsubsection{Electroacatalytic activity of metalloproteins}

So far we have proved that direct electron communication is possible between the active redox center of the immobilized protein and the carbon electrode. We have concluded that carbon nanotube materials, either as CNT forest or as CNT composites, exhibit improved electrochemical performance compared to the graphite composites. In the case of the forest CNT, increased electron transfer kinetics is achieved whether in the case of the CNT composites, their high degree of porosity facilitates the immobilization of more amount of protein and therefore the electrochemical signal is amplified.

In this section, we will demonstrate that the protein immobilization process on CNT also preserves the bioactivity of the protein to typical analytes $\left(\mathrm{O}_{2}\right.$ and $\left.\mathrm{H}_{2} \mathrm{O}_{2}\right)$.

\subsubsection{Electroacatalytic activity in presence of oxygen}

The results reported above have shown the reversible behavior of the redox active core of myoglobin in anaerobic conditions. However when the metalloproteins are exposed to oxygen, a strong catalytic effect appears. Figure 5 comparatively shows the remarkable changes in the electrochemical response of myoglobin in absence or in presence of oxygen. In aerobic conditions the electrocatalytic effect is reflected in an increase of the Fe(III) reduction peak accompanied by the disappearance of Fe(II) oxidation peak (Zhang, 2004; Zhao, 2006; Zhao, 2006 a; Zhang, 2007; Li, 2006).

Such catalytic effect can be explained by the following path. As the potential is cathodically scanned, the direct electrochemical reduction of Protein-Fe(III) to Protein-Fe(II) takes place at the carbon electrode. Fe(II) has a very high affinity for oxygen and the latter process is immediately followed by a fast reaction of Protein-Fe(II) with oxygen. The product of Protein$\mathrm{Fe}(\mathrm{II})-\mathrm{O}_{2}$ could then undergo again electrochemical reduction at the potential of Protein-Fe(III) reduction, producing $\mathrm{H}_{2} \mathrm{O}_{2}$ and Protein-Fe(II). Protein-Fe(II) again reacts fast with $\mathrm{O}_{2}$ to continue the cycle. This scheme of reactions is consistent with the large cathodic wave (due to the catalytic reduction of $\mathrm{Fe}(\mathrm{II})-\mathrm{O}_{2}$ ) and the disappearance of the $\mathrm{Fe}(\mathrm{II})$ anodic wave (due to the fast reaction of Fe(II) with oxygen) (Nakajima, 1987; Onuoha, 1997; Zhang, 2002). 


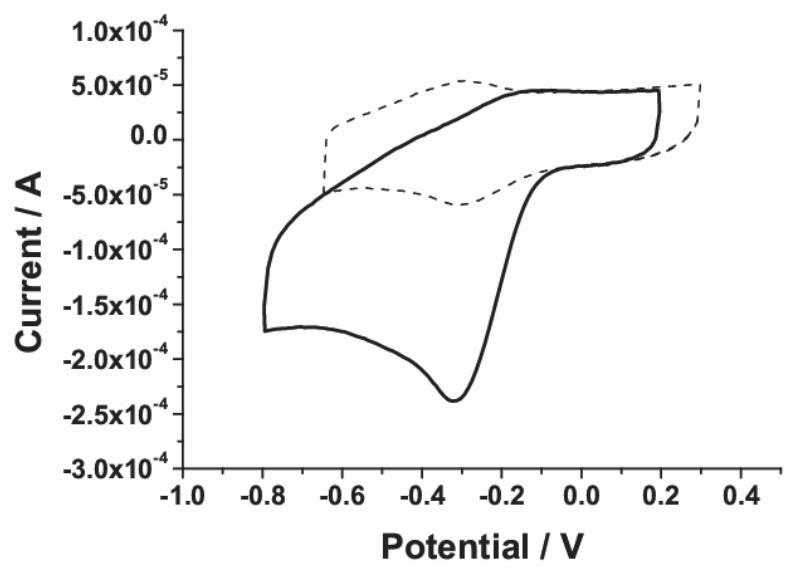

Fig. 5. Cyclic voltammograms for a forest like CNT electrode modified with Myoglobin in deareated PBS solutions (dashed curve) and air saturated PBS solutions (solid curve). Scan rate: 0.1 V/s. Reproduced with permission from (Esplandiu, 2009a). Copyright, 2009, IOP Publishing.

\section{Electrochemical response on different substrates}

In this section we will compare the electrocatalytical behavior of $\mathrm{Mb}$ in presence of oxygen when immobilized on different electrodes. Firstly, Fig. 6 shows the behavior of the electrochemical response of the different $\mathrm{Mb}$-modified carbon electrodes in an aerated solution. Fig. 6 also shows, as a reference, the voltammograms of protein-free carbon electrodes, where there was no signature of a peak, at least in the scanned potential window.

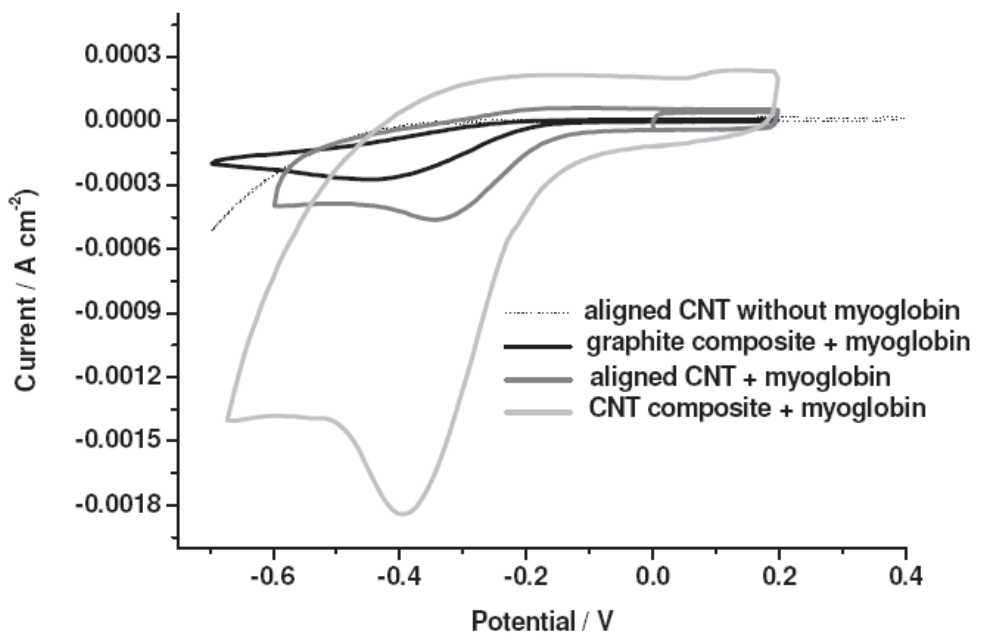

Fig. 6. I/V profiles for the different carbon electrodes in aerated PBS solutions at a scan rate of $0.1 \mathrm{~V} / \mathrm{s}$. Reproduced with permission from (Esplandiu, 2009a). Copyright, 2009, IOP Publishing. 
It can be observed that in terms of current density, the CNT composite exhibits the higher values, followed by the forest like CNTs, and the graphite composite. The reason for that has to do with the protein coverage on the different carbon based systems, as discussed previously. The sensitive response of $\mathrm{Mb}$ to oxygen also demonstrates that the immobilization procedure on such carbon systems does not perturb the bioactivity of the protein.

We have also followed the catalytic behavior of $\mathrm{Mb}$ in presence of oxygen but when immobilized in other electrodes such gold and HOPG (Pacios, 2009). Figure 7 shows the $\mathrm{Mb}$ /electrode response normalized to the same geometric area. Three voltammogram scans are depicted for each electrode material; they were taken with three minutes of difference among them. The poor voltammetric response achieved in the case of HOPG and Au electrodes is remarkable. The oxygen catalytic response progressively disappeared in different $\mathrm{i} / \mathrm{V}$ runs in the case of $\mathrm{Au}$ and HOPG which can reflect either difficulties in anchoring firmly the protein on such electrode surfaces or a progressive denaturation of the protein with the consequent loss of its bioactivity. However, a more stable and reproducible response was kept at the forest CNT substrates. In the results presented in Fig. $7 \mathrm{a}, \mathrm{b}$ and $\mathrm{c}$, $\mathrm{Mb}$ has been physisorbed on the forest CNT, HOPG and Au electrodes. At this point it is worth mentioning that physisorbed $\mathrm{Mb}$ on CNT forest behaves similarly as the covalently attached $\mathrm{Mb}$. The main difference between the system with a higher degree of covalently attached protein and the one with only physisorbed biomolecules is reflected in the long term electrode lifetime. We verified that covalently attached $\mathrm{Mb} / \mathrm{CNT}$ systems could provide reproducible response up to a month with only a reduction of the electroactivity of about $15 \%$, whereas $\mathrm{Mb}$ physorbed on $\mathrm{CNT}$ electrodes exhibited stable electroactivity response only for a maximum of one week (Pacios, 2009).
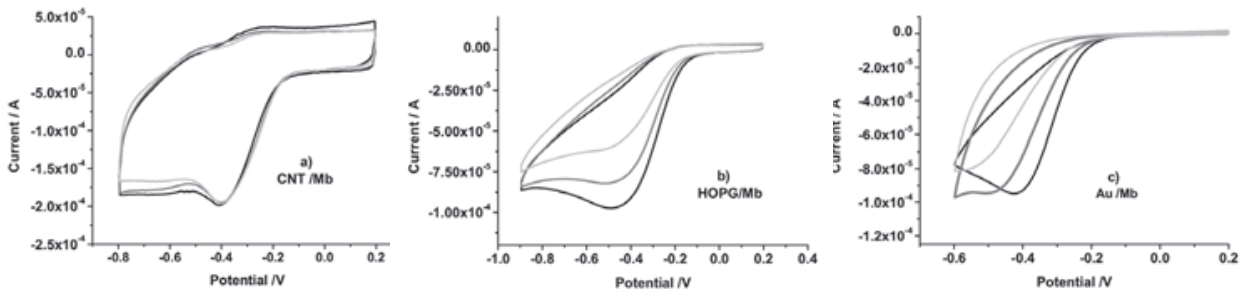

Fig. 7. Oxygen reduction catalytical signal for different electrode surfaces in PBS solutions at $0.1 \mathrm{~V} / \mathrm{s}$. Three cyclic repetitive runs are shown for each electrode taken with a difference of three minutes among them (black line: 1st cycle; grey: 2nd cycle; light grey: 3rd cycle). Reproduced with permission from (Pacios, 2009) only plots b and c. Copyright, 2009, American Scientific Publishing.

\subsubsection{Electrocatalysis of hydrogen peroxide}

In this section, we will present the catalytic activity of myoglobin in presence of hydrogen peroxide when carbon-based electrodes are used. By adding aliquots of $\mathrm{H}_{2} \mathrm{O}_{2}$ to the PBS solution, a considerable increase of the reduction peak was observed at about the same potential at which the electrocatalytic oxygen reduction was taken place. The disappearance of the anodic peak was also detected. All these features can be observed in Fig. 8, in which the behavior of the vertically aligned CNT electrode is taken as a representative example. A reference test using the carbon electrodes in absence of protein but in presence of different 
concentrations of $\mathrm{H}_{2} \mathrm{O}_{2}$ showed no obvious cathodic peak response, at least in the potential range under study. The catalytic reduction of $\mathrm{H}_{2} \mathrm{O}_{2}$ exhibits a behavior similar to the one found with oxygen, which suggests that the reaction mechanisms could be similar. Several plausible explanations have been provided in the literature (Nakajima, 1987; Onuoha, 1997; Zhang, 2002), under the assumption that $\mathrm{H}_{2} \mathrm{O}_{2}$ can act as an oxidant or reductant agent. It has been suggested that $\mathrm{H}_{2} \mathrm{O}_{2}$ reacts with $\mathrm{MbFe}(\mathrm{III})$ to give an oxyferryl radical $(\cdot \mathrm{MbFe}(\mathrm{IV})=\mathrm{O})$ which can react again with $\mathrm{H}_{2} \mathrm{O}_{2}$ to produce oxygen and $\mathrm{Mb}(\mathrm{III})$. When $\mathrm{MbFe}(\mathrm{III})$ is reduced at the electrode, it can react fast with oxygen and follow the same path described in the previous section for the oxygen.

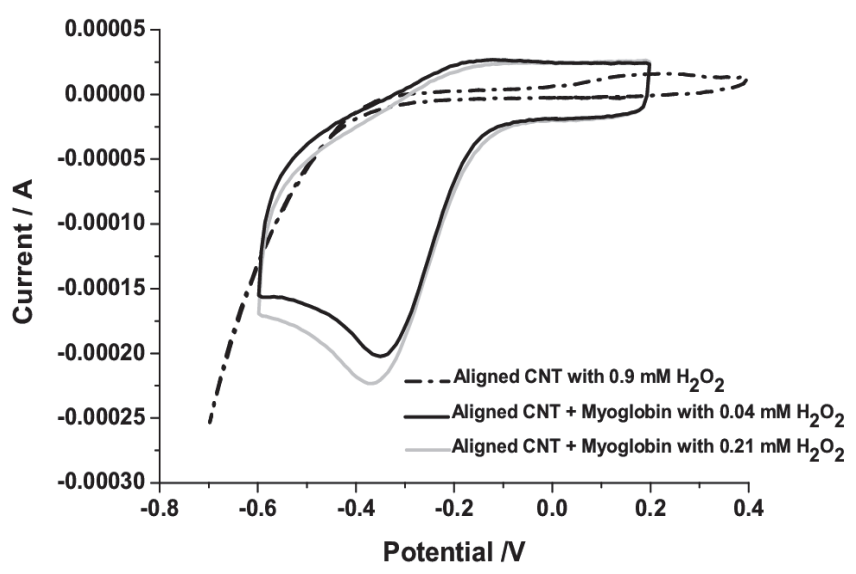

Fig. 8. I/V profiles for the vertically aligned CNT electrode modified with $\mathrm{Mb}$ in PBS solutions under different concentrations of $\mathrm{H}_{2} \mathrm{O}_{2}$ at a scan rate of $0.1 \mathrm{~V} / \mathrm{s}$. The electrochemical behaviour of $\mathrm{CNT}$ in absence of $\mathrm{Mb}$ was also included. Adapted from (Esplandiu, 2009a).

In order to have a closer inspection of the electroanalytical parameters, calibration curves were performed on the three carbon electrodes by analizing the current density changes at the catalytic peak as a function of the $\mathrm{H}_{2} \mathrm{O}_{2}$ concentration (Esplandiu, 2009a). From such calibration curves one would expect a zone of linear response to the analyte that makes possible to extract the sensitivity of the electrochemical response, the limit of detection (LOD) and the range of linear behavior. Table 2 summarizes the electroanalytical characteristics of the myyoglobin graphite composites, CNT composites and CNT forest electrodes.

\begin{tabular}{|c|c|c|c|}
\hline Electrode & LOD & Sensitivity $\left(\mathrm{Acm}^{-2} \mathrm{M}^{-1}\right)$ & Linear range \\
\hline Graphite Composite & $9.10^{-5} \mathrm{M}$ & 0.10 & Small \\
\hline CNT composite & $6.10^{-5} \mathrm{M}$ & 0.84 & wide \\
\hline Forest CNT & $5.10^{-8} \mathrm{M}$ & 0.47 & wide \\
\hline
\end{tabular}

Table 2. Electroanalytical parameters for the detection of hydrogen peroxide on the different carbon based electrodes. 
In the case of the graphite epoxy composites, the limit of detection (LOD) for hydrogen peroxide was of $9.10^{-5} \mathrm{M}$, the sensitivity, extracted from the curve slope, was of $0.14 \mathrm{~A} \mathrm{~cm}^{-2} / \mathrm{M}$ and the linear behaviour extended for a reduced range of concentrations (Fig. 9 a). Above a certain concentration (between $6.10^{-4}$ and $1.10^{-3} \mathrm{M}$ ), the electrode reached saturation and upon further addition of $\mathrm{H}_{2} \mathrm{O}_{2}$ the current density slightly decreases probably due to a partial protein inactivation in the presence of a higher concentration of peroxide. In the case of the carbon nanotube composite (Fig. 9 b), it was obtained a good calibration curve with a LOD around $6.10^{-5} \mathrm{M}$, wide range of linear behavior and remarkable high sensitivity of about $0.84 \mathrm{~A} \mathrm{~cm}^{-2} / \mathrm{M}$. Vertically aligned CNT electrode exhibited very low detection limits (LOD around $5.10^{-8} \mathrm{M}$ ), a sensitivity of $0.47 \mathrm{~A} \mathrm{~cm}^{-2} / \mathrm{M}$ and a very important wide linear concentration range (Fig. $9 \mathrm{c}$ ). Among the different analyzed electrode systems, the high signal/noise ratio of the vertically aligned CNT electrode at such low $\mathrm{H}_{2} \mathrm{O}_{2}$ concentration is remarkable, which could be a consequence of a facilitated electron transfer process of the protein in such environment. In order to have a better quantification of the sensitivity of the different electrodes to the analyte, a normalization of the curves with respect to their electrochemically active protein coverage was made. At the same electroactive protein coverage, the verticallyaligned CNT electrode is almost two times more sensitive than the case of the CNT composite. Thus the higher apparent sensitivity of the CNT composite electrode can be only ascribed to the larger protein coverage due to the higher degree of porosity of this electrode.
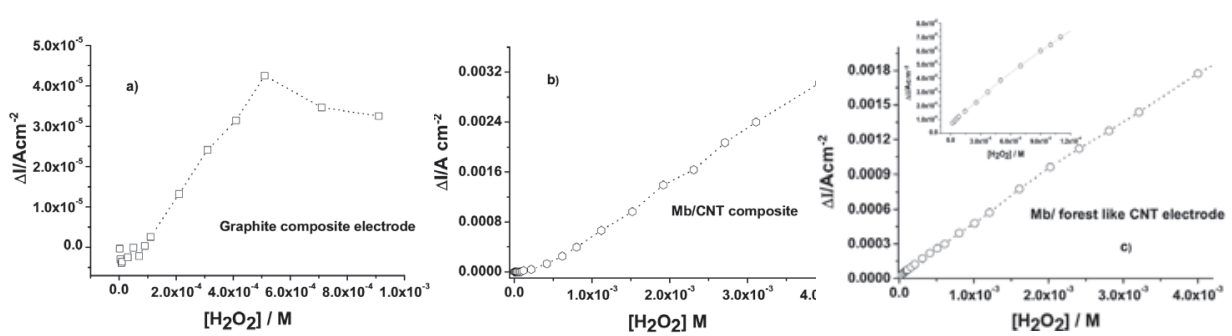

Fig. 9. Calibration curves of hydrogen peroxide on the different $\mathrm{Mb} /$ carbon based electrodes. In the forest like system an inset of the curve at the lower concentrations has also been included. Reproduced with permission from (Esplandiu, 2009a). Copyright, 2009, IOP Publishing

These results highlight the good electrochemical performance of electrodes made by a vertical disposition of CNT. The reasons underlying this enhanced performance could be attributed to the fact that this particular configuration results in a more suitable environment for the covalent anchoring of the protein, providing a favourable orientation of the proteins on the tubular structure while keeping a robust protein immobilization. At the same time, the vertical arrangement of CNT facilitates a high surface density of CNT edges, which have been shown to exhibit an improved and fast electron transfer response. All these features can result in a faster electrode response and consequently in a better electron coupling with the protein system. 


\subsection{DNA modified CNT electrode: Detection of DNA hybridization by using reversible redox indicators}

As stated in the introduction, the use of redox reporter molecules for following up the hybridization process is a simple and straightforward method that avoids sample damage or the chemical modification of the DNA. We have used electrostatic groove redox binders based on highly positively charged ruthenium complexes which are expected to accumulate at the electrode interface with the hybridization process. The work has been developed by using mainly forest CNT microelectrode arrays, although the electrochemical response of CNT dispersed on glassy carbon electrodes to the DNA recognition was also followed. PolyC-NH 2 , used as probe, was covalently attached to the CNTs and then PolyG was used as target in presence of $\mathrm{Ru}\left(\mathrm{NH}_{3}\right)_{6}{ }^{2+/ 3+}$. We monitored the $\mathrm{Ru}\left(\mathrm{NH}_{3}\right)_{6}{ }^{2+/ 3+}$ electrochemical signal before and after the hybridization process by cyclic voltammetry (CV), chronocoulometry and impedance measurements. We also performed calibration curves by adding increasing concentrations of target PolyG on the probe modified CNT electrode. It will be demonstrated that the combination of CNT microelectrode arrays, the chosen redox indicators and the impedance technique turns out to be a simple and practical methodology for a fast approach to the genosensing process.

\subsubsection{Cyclic voltammetry}

Cyclic voltammetry is a fast approach to detect the hybridization scheme. Although it does not exhibit the high sensitivity of the other two techniques that will be shown later on, it is very suitable for providing a general trend in the hybridization process. We have found that as the concentration of the target DNA is increased, an augment of the peak current and a decrease in the peak potential difference are observed. Such features indicate an electrostatic surface accumulation of the cationic redox marker due to the increase of the negatively charged oligonucleotide phosphates with the increasing hybridization. Figure 10 a shows this effect for
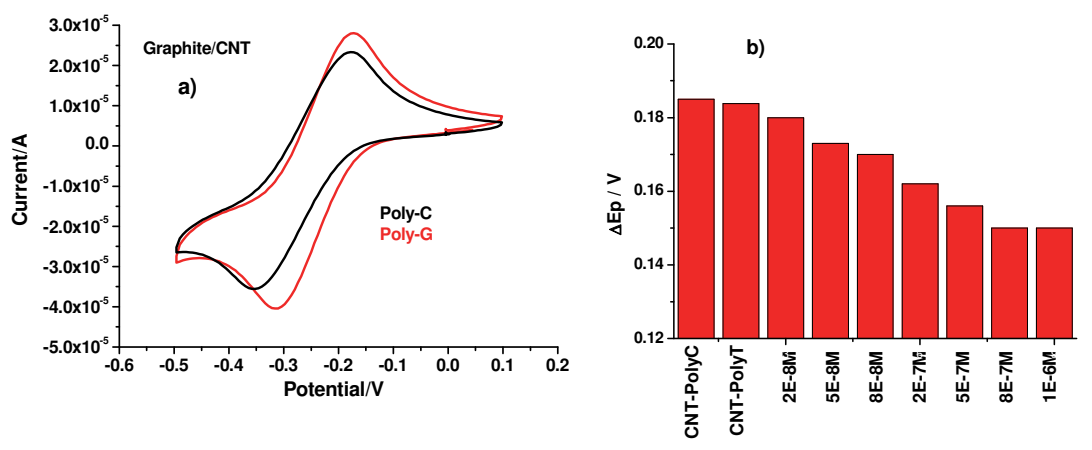

Fig. 10. a) Cyclic voltammograms for CNT/glassy carbon electrode modified with covalently attached PolyC and after immersion in 1.10-6 M Poly-G. b) Peak potential difference histogram of CNT/glassy carbon electrode with covalently attached PolyC in presence of non-complementary $1.10^{-6} \mathrm{M}$ polyT and in presence of increasing of complementary PolyG targets. In all the cases the electrodes were blocked with PEG for avoiding non-specific adsorption. The electrolyte was $1.8 \mathrm{mM} \mathrm{Ru}\left(\mathrm{NH}_{3}\right)_{6}{ }^{3+}$ in Tris and was deoxygenated with $\mathrm{N}_{2}$ bubbling for 5 minutes prior to measurements. 
a CNT/glassy carbon electrode modified with probe DNA and Fig. $10 \mathrm{~b}$ shows the peak potential difference for the the same electrode in presence of increasing aliquots of target oligonuleotides. Such accumulation of the cationic redox marker at the electrode interface makes electron transfer kinetics of the redox probe more favorable. That is sensitively reflected in a peak potential difference decrease. Negative controls in the hybridization process were also obtained by targeting the probe modified electrode with a non-complementary strand such as PolyT.

It is worthy to mention that these features were also found in CNT microelectrode arrays functionalized with PolyC, immersed in increasing concentrations of PolyG strands. These results demonstrate that both CNT platforms are able to anchor the DNA probe and follow the hybridization process. However, this technique can not discriminate between the redox response of the ruthenium species diffusing from the solution and those ones electrostatically adsorb on the phosphate backbone when both of them are present simultaneously. For discrimination of both kinds of species, chronocolumetric measurements can be performed.

\subsubsection{Chronocoulometric measurements}

Chronocoulometry measurements can help to estimate the accumulated cationic redox marker at the oligonucleotide CNT modified surface as indicative of the hybridization process (Steel, 1998).

In this method a pulse of potential is applied and the response in current is monitorized as a function of the time. From the integration of the current profiles vs time, one can obtain the charge (Q). Chronocoulometry is useful for measuring electrode surface areas, diffusion coefficientes, adsorption of electroactive species and the mechanisms and rate constants for chemical reactions coupled to electron transfer reactions.

The total charge $\left(\mathrm{Q}_{\text {total }}\right)$ measured in response to the potential step comes from three sources (eq. 1) :

1. Charge of the double layer $\left(\mathrm{Q}_{\mathrm{dl}}\right)$ which dominates at shorter times

2. Charge of the adsorbed species ( $\left.Q_{a d s}\right)$

3. Charge of the species diffusing at the electrode $\left(Q_{\text {diff }}\right)$ which dominates at longer times.

$$
Q_{\text {TоT }}=Q_{d l}+Q_{a d s}+Q_{d i f f}=Q_{d l}+n F A \Gamma_{o}+\frac{2 n F A D_{o}^{1 / 2} C_{o}}{\pi^{1 / 2}} t^{1 / 2}
$$

$\mathrm{F}$ is the Faraday constant $(96500 \mathrm{C}), \mathrm{A}$ is the electrode area, $\mathrm{n}$ the number of electrons and $\mathrm{C}_{\mathrm{o}}$ is the concentration of the redox species at the bulk electrolyte, $\mathrm{D}$ is the diffusion coeficient of the species and $\Gamma_{\mathrm{o}}$ is the amount of adsorbed species at the interface of the electrode.

In order to estimate the charge corresponding to the electroactive species adsorbed on the surface, one has first to substract the double layer charge (Steel, 1998). Accordingly, we have performed chronocoulometric measurements with the background electrolyte (in absence of the electroactive species that undergo adsorption on the electrode). By extrapolation of a least squares fit from the linear part of the curve charge vs $t^{1 / 2}$, one can obtain the double layer charge $\left(\mathrm{Q}_{\mathrm{dl}}\right)$ from the the intercept at time zero. Then the chronocoulometric measurements are performed in presence of the redox markers and again the interception at zero time is estimated which corresponds to the charge of the double layer + the charge of the adsorbed amount. Therefore, from both measurements one can get the adsorbed amount by $Q_{d l}$ substraction (Fig. 11). As compared to $C V$, the chronocoulometry has the advantage 
that the double layer charge and the charge due to the redox reaction of species adsorbed on the electrode surface can be differentiated from the charge due to the redox reaction of the molecules that diffuse to the electrode. That prevents the confussion over which concentration is being measured, thus symplifying the analysis.

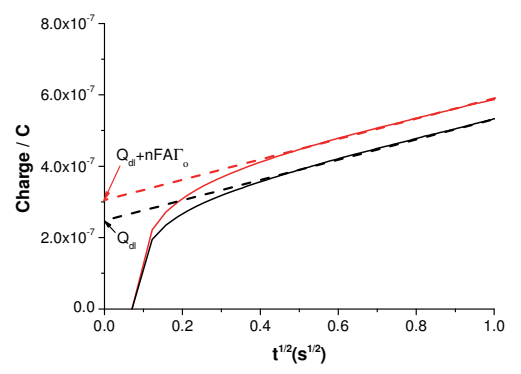

Fig. 11. Illustration of the procedure in order to get the amount of electroactive species adsorbed on an CNT/PolyC electrode. First the chronocoulometric measurements were performed in the background electrolyte, buffer solution of $10 \mathrm{mM}$ TRIS $+10 \mathrm{mM} \mathrm{NaCl}$ (black curve) in order to extract the $\mathrm{Q}_{\mathrm{dl}}$. Then the solution was changed to $50 \mu \mathrm{M}$ of $\mathrm{Ru}\left(\mathrm{NH}_{3}\right)_{6}{ }^{3+}$ in TRIS $+\mathrm{NaCl}$ in order to determine the amount of the adsorbed redox species (red curve). Potential pulse from $0.1 \mathrm{~V}$ to $-0.4 \mathrm{~V}$ and duration time of $0.5 \mathrm{~s}$.

We have performed such procedure to calculate the charge corresponding to the amount of electroactive species adsorbed on the electrode $\left(Q_{a d s}=n F A \Gamma_{0}\right)$. The values of $Q_{a d s}$ have been taken as indicators of the hybridization process (Steel, 1998). In the low ionic strength buffer solution we are using, the trivalent ruthenium species preferentially exchanges with the native monovalent DNA counterion and associates with the phosphate groups in a ratio 1:3. Figure 12 shows the $Q_{\text {ads }}$ as a function of increasing aliquots of target DNA for the CNT microelectrode. It can be observed that the probe modified electrode is very sensitive to concentrations below $2.510^{-7} \mathrm{M}$ of the target and then a saturation is reached. The limit of detection in such CNT microelectrode system was found to be around $1 \mathrm{nM}$. Controls with non-complementary strand showed no increase in the charge associated with the electrode surface.

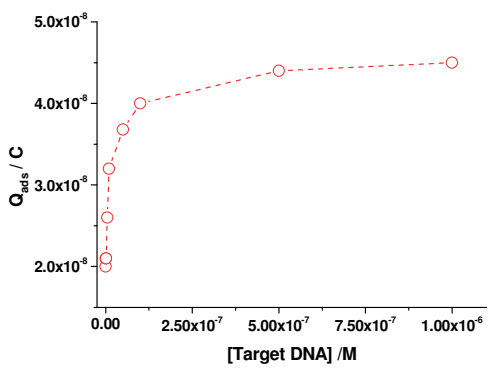

Fig. 12. Q Qds on a CNT microelectrode array chemically modified with PolyC and as a function of increasing concetrations of target PolyG. 
The use of this technical tool in combination with CNT platforms has been demonstrated to be a quite sensitive strategy to monitor the hybridization process. One can also go a step forward and calculate $\Gamma_{\mathrm{o}}$ from $\mathrm{Q}_{\text {ads }}$ to get more details in the hybridization process (Steel, 1998). Although we will not cover such calculation in this chapter, it is worthy to mention that from $\Gamma_{\mathrm{o}}$ it is possible to get the density of the immobilized DNA on the surface of the electrodes and by calculating the amount of DNA before and after the hybridization, the number of probe and target DNA strands attached to the electrode surface and the hybridization efficiency can be calculated (Steel, 1998).

\subsubsection{Electrochemical Impedance Spectroscopy}

Electrochemical Impedance Spectroscopy (EIS) is a technique which is used to characterize electrode processes and complex interfaces. This method is based on the application of an $\mathrm{AC}$ potential $\left(\mathrm{E}(\mathrm{t})=\mathrm{E}_{\mathrm{o}} \cos (\omega+\mathrm{t})\right.$ ) of small amplitude (typically $10 \mathrm{mV}$ ). As a consecuence an AC current is obtained, $I(t)=I_{0} \cos (\omega t-\varphi)$. From the relation of both signals the impedance $(Z)$ is obtained $(Z=E(t) / I(t))$. The measurements are carried out at different $\mathrm{AC}$ frequencies and thus the name of impedance spectroscopy. Typical frequency range is $0.5 \mathrm{~Hz}$ to $100 \mathrm{kHz}$. Impedance methods allows characterizing the double layer interface at the electrodes and the physicochemical processes of widely differing time constants, sampling electron transfer at high frequency and mass transfer at low frequency. Impedance results are commonly fitted to equivalent circuits of resistors and capacitors, such as the Randles circuit shown in Fig. 13, which is often used to interpret simple electrochemical systems. There are many ways to plot impedance data. Since the function impedance is an AC signal, one can express it in terms of complex number $\left(Z=Z_{\text {real }}+j Z_{\text {imag }}\right)$ and plot the $Z_{\text {real }}$ vs $Z_{\text {imag }}$ such kind of representation is called Nyquist plot shown in Fig. 13, which provides visual insight into the system dynamics at the electrochemical interface. Normally such plot exhibits a kind of semicircle profile plus a linear region. The points at which the impedance data cut the real impedance data represent resistance values. In the typical plot of the figure $R_{c t}$ is the charge-transfer resistance, which is inversely proportional to the rate of electron transfer and consequently provides us information about the easiness for electron transfer at the electrode interface (a rough estimation of $R_{c t}$ is related with the diameter of the semicircle); $C_{d}$ is the double-layer capacitance and can be obtained from the maximum value of impedance data at the semicircle; $R_{s}$ is the electrolyte resistance and can be extracted from impedance data at the higher frequencies; $Z_{\mathrm{w}}$ is the Warburg impedance and is identified with the linear portion of the impedance spectra that appears at the lower frequencies. The Warburg impedance arises from mass-transfer limitations and can be used to measure effective diffusion coefficients.

Another way to represent the impedance results is by using the Bode Plot where the modulus of the impedance $(\log |\mathrm{Z}|)$ and the phase angle $(\varphi)$ between the AC potential and the AC current as a function of the frequency $(\log \omega)$ are plotted (Fig. 13). In this plot, the impedance data which are frequency independent represent the behavior of the resistive processes (phase angles close to 0 ) whereas the ones that are dependent on the frequency are more related to capacitive or diffusive processes (phase angles between $-90^{\circ}$ or $-45^{\circ}$ ) . Thus the impedance spectra can give us a broad overview of the different processes taking place at the electrochemical interface (capacitive, resistive, diffusion effects) and which one is dominating more at a specific range of frequencies. 


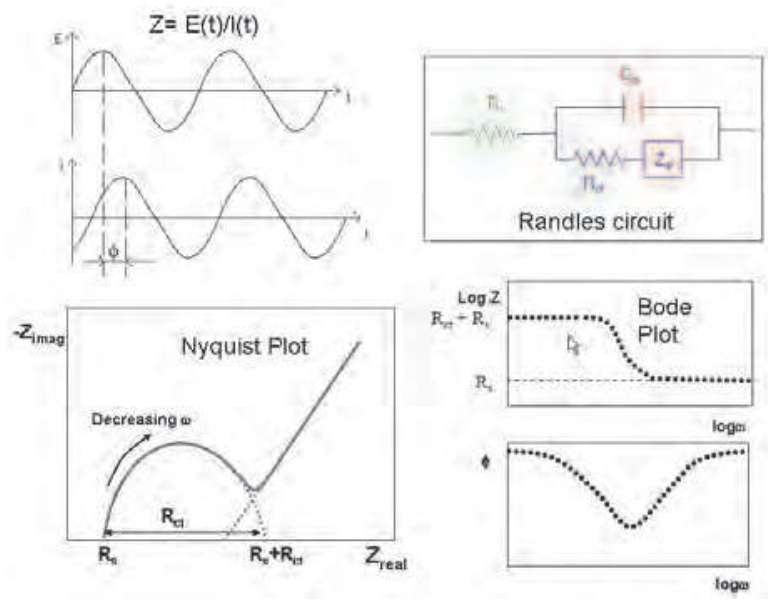

Fig. 13. Impedance function and typical equivalent circuit at the electrochemical interface (the Randles circuit). Different representations of the impedance data (Nyquist and Bode plots)

Impedance spectroscopy is a very versatile tool widely used in different fields (corrosion, semiconductor electrodes, polymers and coatings, batteries, fuel cells, electrode kinetics and mechanisms, biomedical and biological systems, solid-state systems, etc.). Since EIS turns out to be very sensitive to probe the interfacial properties it has become an attractive tool to monitor biorecognition processes at the electrode surface such as in immunosensing or in genosensing fields. This technique also offers the added value of monitoring processes in label free conditions. From the considerable amount of papers dealing with EIS in the electrochemical biosensing area, part of them deals with non-faradaic measurements based on the monitoring of the capacitance values and the other part relies on the used of redox indicators to monitor the changes in the charge transfer resistance.

We have also profited from this technique and performed impedance measurements to follow the hybridization process. Before going in the details of such approach, we would like to mention an important aspect of this study which has to do with the scaling down of the electrode size and its effect on the impedance spectra. Since we are performing impedance spectra in presence of a redox active reporter $\left(\mathrm{Ru}\left(\mathrm{NH}_{3}\right)_{6}{ }^{2+/ 3+}\right.$, the more approppiate impedance parameter to probe the interfacial changes is the charge transfer resistance $\left(R_{\mathrm{ct}}\right)$. In contrast to other widely used redox probes such as $\mathrm{Fe}(\mathrm{CN})_{6}^{3-/ 4-\text {, the }}$ ruthenium electroactive species is well known to be a more reversible redox pair and also it does not physiadsorb on carbon electrodes, which makes the use of this redox probe quite desirable for many applications. However and due to its high electron kinetics, the $R_{c t}$ analysis of interfacial processes on metallic macroelectrodes becomes impossible. In such cases the impedance spectra is fully dominated by the Warburg impedance, that is, the electrochemical process is diffusion controlled. However, the diffusion control of the electrochemical process can start to decrease when the size of the electrode is reduced. Figure 14 shows this transition from diffusion to electron kinetics control due to a decrease in the electrode area and therefore an increment of the system impedance. The Nyquist plot changes from a straight line (Warburg impedance control by using macroscopic forest CNT 
electrode) to a semicircle (charge kinetics control by using CNT microelectrode array). Similar changes have been observed in carbon nanofiber electrode arrays (Siddiqui, 2010). Such change in the control process at the electrochemical interface has a real advantage in our case. The impedance detection of the hybridization process based on the charge transfer resistance of the ruthenium reporters is now possible if CNT microelectrodes are used. Under these conditions one can take the $R_{c t}$ parameter as indicative of the hybridization process.
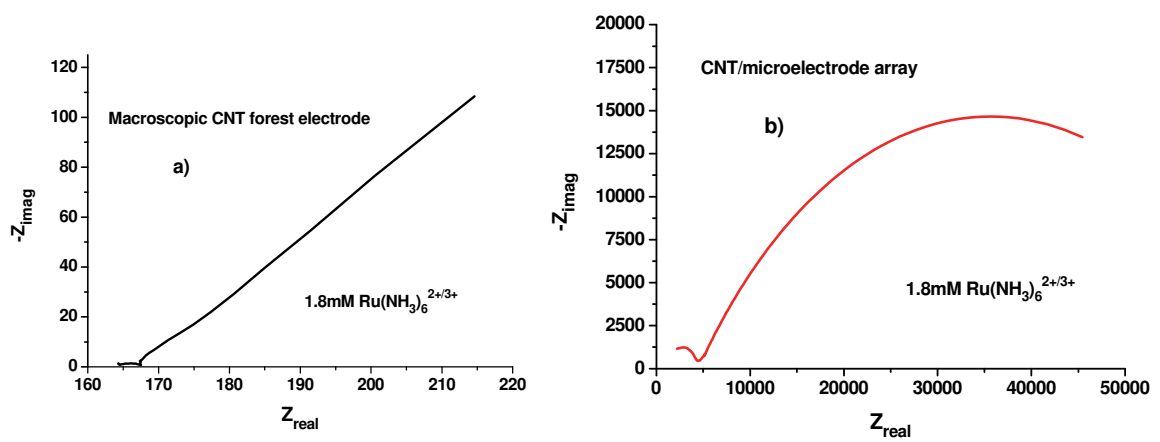

Fig. 14. Impedance spectra of a macroscopic CNT forest electrode (a) and a CNT microelectrode array in presence of $1.8 \mathrm{mM} \mathrm{Ru}\left(\mathrm{NH}_{3}\right)_{6}{ }^{2+/ 3+}(\mathrm{b})$. It can be observed the transition of the impedance spectra from a diffusion-controlled system to a more kineticcontrolled one with the scaling down of the electrode size.

We have performed the monitoring of the hybridization process on the CNT microelectrode array. The parameter $R_{c t}$ was obtained by fitting the impedance spectra to the equivalent circuit depicted in Fig. 13 but without the Warbug parameter and with the double layer capacitance being reresented by a constant phase element (CPE), a parameter that takes into consideration the inhomogeneities of the electrode. The impedance of a $\mathrm{CPE}$ is $Z_{C P E}=C^{-1}(j \omega)^{-1}$, where $C$ is the capacitance and $n$ is a fitting parameter that can vary from 0 to 1 . When $n=1$, the constant phase element approaches the value of a pure capacitance. In our case, $\mathrm{n}$ was ranging between $0.78-0.73$.

The quantitative values of $R_{\text {ct }}$ have been plotted in Fig. 15 as a function of increasing target concentrations. As mentioned before, this parameter provides us information about the easiness for electron transfer at the electrode interface, and the trend of this parameter is similar to the findings of the cyclic voltammetry. $\mathrm{R}_{\mathrm{ct}}$ decreases as the cationic redox marker is accumulated on the interface due to the surface increase of negatively charged phosphates. The electrostatic attraction of the redox marker facilitates the electron exchange as the hybridization process is taken place. The change in resistance is again very sensitive at concentrations below $2.510^{-7} \mathrm{M}$. Above such concentration the charge transfer resistance reaches a plateau. Limits of detection were calculated to be around 1. 10-10 M demonstrating the high sensitivity of this technique.

The results of this section allow us to stress the power of the impedance technique in monitoring biorecognition events with a simple hydridization detection scheme. This approach could not have been achieved without the versatility of the CNTs to be disposed in a microelectrode array configuration. 


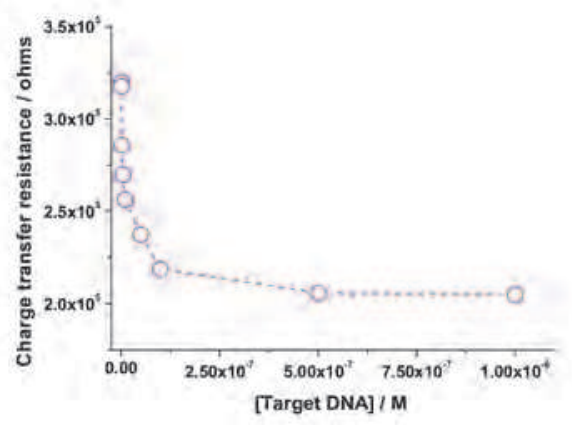

Fig. 15. Impedance spectra of the probe modified CNT microelectrode performed with 1.8 $\mathrm{mM} \mathrm{Ru}\left(\mathrm{NH}_{3}\right)_{6}{ }^{3+}$ in PBS with increasing concetrations of target DNA. The electrolyte was deoxygenated with $\mathrm{N}_{2}$ bubble for 5 minutes prior to measurements. The impedance was performed with PBS or $1.8 \mathrm{mM} \mathrm{Ru}\left(\mathrm{NH}_{3}\right)_{6}{ }^{3+/ 2+}$ in TRIS at $-0.26 \mathrm{~V}$ potential, $10 \mathrm{mV}$ amplitude, from $300 \mathrm{mHz}$ to $100 \mathrm{kHz}$ lower and upper limit.

\section{Conclusion and future directions}

In this chapter we have tried to highlight the electroanalytical CNT properties for biosensing applications. The remarkable electrochemical properties of CNT arise as a combination of different aspects given mainly by their surface structure, nanometric size and aspect ratio, their high specific area, their electrochemical anisotropy and their versatility to be disposed in different electrode configurations.

We have illustrated two examples that demonstrate the suitability of CNT as electrochemical transducers in enzymatic and DNA sensors. In the first example, we have proven that carbon nanotubes-based materials exhibit an enhanced electrochemical response towards Myoglobin as compared to other electrode substrates. The CNT systems represent an adequate platform for the protein wiring which allows on one side the direct electrochemistry between the hemin active redox center of the protein and on the other side the preservation of the protein bioactivity to different substrates (oxygen, hydrogen peroxide, etc.). We have tested two different CNT electrodes: forest CNT and epoxy CNT composite electrodes. In the former CNT electrode, the enhanced electrochemical signal could arise from a more facilitated electron transfer. This seems to be a consequence of the exposition of a higher density of the more electroactive sites (edge sites), just at the electrode/solution interface. That could facilitate the wiring and electron exchange with $\mathrm{Mb}$.

In the case of the CNT composites, the electrochemical improvement comes from the more porous character of this material and consequently higher surface area for the immobilization of more amount of protein which amplifies the signal response. All these aspects exert influence in the final electroanalytical characteristics such as the remarkable low detection limits in the response of the protein to its specific substrates (case of the $\mathrm{Mb}$ /forest CNT electrodes), the high sensitivity due to the large protein loading (case of the CNT composite electrodes) and the wide analyte concentration range. Indeed all these features encourage the use of $\mathrm{Mb} / \mathrm{CNT}$ electrodes as efficient sensors for oxygen, hydrogen peroxide or nitric oxide with could bring impact in clinical and environmental applications. 
The second example reported here is about the use of electrochemical CNT transducers in genosensors. In our studies, we have mainly used a microelectrode array made of vertically aligned CNTs as electrode platform. That electrode system results in a robust platform for single point linkage of probe DNA and for following up the hybridization process with a simple and reversible detection scheme based on electrostatic groove redox binders which are positively charged. Different electrochemical techniques were used such as Cyclic Voltammetry, Chronocoulometry and Impedance Spectroscopy. Chronocoulometry allowed us to discriminate the accumulated redox species at the interface from those diffusing in the electrolyte. The monitoring of the accumulated species provided us a sensitive way to follow the DNA hybridization. On the other side, the combination of the CNT microelectrode array, together with the impedance measurements turned out to be a powerful approach to follow the hybridization process with such highly positively charged redox indicators. It is worthy to mention that without such CNT microelectrode and the scaling down size effects of the electrode on the impedance measurements it should have not been possible to characterize the biorecongition process with that simple but sensitive approach. Again all these results hold promise for the development of simple, and practical genosensors for many applications.

The two examples of biosensing with CNT platforms reported in this chapter encourage the exploitation of novel and miniaturized CNT electrode configurations that can be tunable according to different electrochemical applications. Such applications do not remain restricted to the electrochemical biosensing field but can cover other exciting areas such as the development of electrochemical actuators or electrochemical energy-harvesting devices. Acknowledgements. This work was financially supported by the Ministry of Education and Science of Spain (Project NAN2004-093006-C05-03 and CTQ-2006-15681-C02-01). M. Pacios acknowledges a FPI predoctoral grant.

\section{References}

Banks, C.E.; Compton, R.G. (2006) New electrodes for old: from carbon nanotubes to edge plane pyrolytic graphite. The Analyst, 131, (1), pp. 15-21.

Bonanni, A.; Del Valle, M. (2010) Use of nanomaterials for impedimetric DNA sensors: a review. Analytica Chimica Acta, 678, pp. 7-17.

Bonanni, A.; Esplandiu, M.J.; Del Valle, M. (2007) Signal amplification for impedimetric genosensing using gold-streptavidin nanoparticles, Electrochimica Acta, 53 , (11), pp. 4022-4029.

Bonanni, A; Esplandiu, M.J., Del Valle, M. (2009) Impedimetric genosensors employing $\mathrm{COOH}-$ modified carbon nanotube screen-printed electrodes, Biosensors and Bioelectronics, 4 (9), pp. 2885-2891.

Bonanni, A; Esplandiu, M.J.; Del Valle, M. (2010) Impedimetric genosensing of DNA polymorphism correlated to cystic fibrosis: a comparison among different protocols and electrode surfaces. Biosensors and Bioelectronics, 26 (4) pp. 1245-1251.

Cai, C; Chen, J. (2004) Direct electron transfer of glucose oxidase promoted by carbon nanotubes. Analytical Biochemistry, 332, pp. 75-83.

Carot, M.L.; Torresi, R.M.; García, C.D.; Esplandiu, M.J.; Giacomelli, C.E. (2010) Electrostatic and hydrophobic interactions involved in CNT biofunctionalization with short ssDNA. Journal of Physical Chemistry C, 114 (10) pp. 4459-4465. 
Drummond, T.G.; Hill, M.G.; Barton, J.K. (2003) Electrochemical DNA sensors, Nature Biotechnology, 21 (10) pp. 1192-1199.

Dumitrescu, I; Unwin, P.R.; Macpherson, J.V. (2009) Electrochemistry at Carbon Nanotubes: Perspective and Issues. Chemical Communications, (45), pp. 6886-6901.

Esplandiu, M. J.; Pacios, M. Cyganek; L. Bartrolí; J. del Valle, M. (2009a) Enhancing the electrochemical response of myoglobin with carbon nanotube electrodes. Nanotechnology, 20, pp. 355502.

Esplandiu, M.J. (2009). Electrochemistry on Carbon Nanotube modified surfaces, in: Chemically Modified Electrodes, R.C. Alkire, D.M. Kolb, J. Lipkowski, P.N. Ross (Eds.), 57-209, Wiley-VCH Verlag, ISBN 978-3-527-31420-1, Weinheim, Germany.

Fan, C.H.; Plaxco, K.W., Heeger, A.J. (2003) Electrochemical interrogation of conformational changes as a reagentless method for the sequence-specific detection of DNA, Proceedings of the National Academy of sciences of the United States of America, 100 (16) pp. 9124-9137.

Gooding, J.J. (2005). Nanostructuring Electrodes with Carbon Nanotubes: A Review on Electrochemistry and Applications for Sensing. Electrochimica Acta, 50, (15), pp.3049-3060.

Gooding, J.J.; Wibowo, R.; Liu, J.; Yang, W.; Losic, D; Orbons, S.; Mearns, F.J.; Shapter, J.G.; Hibbert, D.B. (2003) Protein electrochemistry using aligned carbon nanotube arrays. Journal of the American Chemical Society, 125, pp. 9006-9007.

Gorodetsky, A.A.; Buzzeo, M.C.; Barton, J.K. (2008) DNA-mediated electrochemistry, Bioconjugate Chemistry, 19 (2), pp. 2285-2296.

Guiseppi-Elie, A; Lei, C.; Baughman, R.H. (2002) Direct electron transfer of glucose oxidase on carbon nanotubes. Nanotechnology, 13 (5) pp. 559-564.

He, P.; Xu, Y.; Fang, Y. (2006) Applications of carbon nanotubes in electrochemical DNA biosensors, Microchimica Acta, 152, pp. 175-186.

He, P.G.; Dai, L.M. (2004a) Aligned carbon nanotube-DNA electrochemical Sensors, Chemical Communications, 3, pp. 348-349.

Heng, L.Y.; Chou, A.; Yu, J.; Chen, Y.; Gooding, J.L. (2005) Demonstration of the advantages of using bamboo-like nanotubes for electrochemical biosensor applications compared with single walled carbon nanotubes, Electrochemistry Communications, 7 (12), pp. 1457-1462.

Jones, C.P.; Jurkschat, K.; Crossley, A.; Compton, R.G.; Riehl, B.L.; Banks, C.E. (2007) Use of high-purity metal-catalyst-free multiwalled carbon nanotubes to avoid potential experimental misinterpretations, Langmuir, 23 (18), pp. 9501-9504.

Katz, E.; Willner, I. (2004). Biomolecule-functionalized carbon nanotubes: applications in nanobioelectronics. ChemPhysChem, 5, (8), pp.1084-1104.

Kim, S.N.; Rusling, J.F.; Papadimitrakopoulos. (2007) Carbon Nanotubes for electronic and electrochemical detection of biomolecules. Advanced Materials, 19, (20), pp. 32143228.

Koehne, J.; Li, J.; Cassell, A.M.; Chen, H.; Ye, Q.; Ng, H.T.; Han, J.; Meyyappan, M. (2004). The fabrication and electrochemical characterization of carbon nanotube nanoelectrode arrays. Journal of Materials Chemistry, 14, pp. 676-684.

Kumar, S.A.; Wang, S.F.; Chang, Y.T.; Lu, H.C.; Yeh, C.T. (2011) Electrochemical properties of myoglobin deposited on multi-walled carbon nanotubes/ciprofloxacin film. Colloids and surfaces B-Intefaces, 82 (2) pp. 526-531. 
Laviron, E. (1979) General expression of the linear potential sweep voltammogram in the case of diffusionless electrochemical systems. Journal of Electroanalytical Chemistry, 101, pp. 19-28.

Li, Y.; Lin, X.; Jiang, C. (2006) Fabrication of a Nanobiocomposite Film Containing Heme Proteins and Carbon Nanotubes on a Choline Modified Glassy Carbon Electrode: Direct Electrochemistry and Electrochemical Catalysis. Electroanalysis, 18, pp. 20852091.

Liu, J.; Chou, A.; Rahmat, W.; Paddon-Row, M.N.; Gooding, J.J. (2005). Achieving direct electrical connection to glucose oxidase using single walled carbon nanotube arrays. Electroanalysis, 17, (1), pp. 38-45.

Martín-Fernández, I. (2010) Thesis: RTCVD synthesis of carbon nanotubes and their wafer scale integration into FET and sensor processes, Barcelona, Spain.

McCreery, R.L. (2008). Advanced Carbon electrode materials for molecular Electrochemistry, Chemical Reviews, 108 (7) pp. 2646-2687.

Moore, R.R.; Banks, C.E; Compton, R.G. (2004) Basal plane pyrolytic graphite modified electrodes: comparison of carbon nanotubes and graphite powder as electrocatalysts. Analytical chemistry, 76, (10), pp. 2677-2682.

Nakajima, R. Yamazaki, I. (1987) The mechanism of oxyperoxidase formation from ferryl peroxidase and hydrogen peroxide. Journal of Biological Chemistry, 262, pp. 2576.

Onuoha, A.C. Zu, X. Rusling, J. (1997) Electrochemical Generation and Reactions of Ferrylmyoglobins in Water and Microemulsions. Journal of the American Chemical Society, 119, pp. 3979.

Pacios, M. ; del Valle, M. ; Bartrolí, J. ; Esplandiu, M.J. (2008). Electrochemical behavior of rigid carbon nanotube composite electrodes. Journal of Electroanalytical Chemistry, 619, pp. 117-124.

Pacios, M.; Del Valle, M.; Bartrolí, J.; Esplandiu, M. J. (2009) Electrocatalyzed $\mathrm{O}_{2}$ Response of Myoglobin immobilized on Multi-Walled Carbon Nanotube Forest Electrodes. Journal of Nanoscience and Nanotechnology, 9, pp. 1-7.

Palangsuntikul R.; Somasundrum, M.; Surareungchai, W. (2010) Kinetic and analytical comparison of horseradish peroxidase on bare and redox modified single-walled carbon nanotubes, Electrochimica Acta, 56 (1) pp. 470-475.

Patolsky, F; Weizmann, Y.; Willner, I. (2004) Long-range electrical contacting of redox enzymes by SWCNT connectors. Angewandte Chemie Int. Ed., 43, pp. 2113-2117.

Pividori, M.I.; Merkoci, A.; Alegret, S. (2003) Graphite-epoxy composites as a new transducing material for electrochemical genosensing, Biosensors and Bioelectronics, 19 (5), pp. 473-484.

Pumera, M.; Merkoci, A.; Alegret, S. (2006) Carbon nanotube-epoxy composites for electrochemical sensing. Sensors and Actuators B-Chemical, 113, (2), pp. 617-622.

Rubianes, M.D.; Rivas, G. (2004) Enzymatic biosensors based on carbon nanotube paste electrodes. Electroanalysis, 17 (1), pp. 73-78.

Salinas-Torres, D.; Huerta, F.; Montilla, F.; Morallón, E. (2011) Study of electroactive and electrocatalytic electrodes surfaces of single walled carbon nanotube-modified. Electrochimica Acta, 56, pp. 2464-2470.

Siddiqui, S; Arumugam, P.U.; Chen, H.; Li, j.; Meyyappan, M. (2010) Characterization of carbon nanofiber electrode arrays using Electrochemical Impedance Spectroscopy: effect of scaling down the electrode size, ACS Nano, 4, (2), pp. 955-961. 
Steel, A.B.; Herne, T.M.; Tarlov, M.J. (1998) Electrochemical quantitation of DNA immobilized on gold, Analytical Chemistry, 70, (22), pp. 4670-4677.

Tasis, D.; Tagmatarchs, N.; Bianco, A.; Prato, M. (2006) Chemistry of Carbon Nanotubes. Chemical Reviews, 106, (3), pp. 1105-1136.

Wang, J. (2005) Carbon-nanotube based electrochemical biosensors: a review. Electroanalysis, 17, (1), pp. 7-14.

Wang, J.; Kawde, A.; Musameh, M. (2003) Carbon nanotube modified glassy carbon electrodes for amplified label-free electrochemical detection of DNA hybridization, The Analyst, 128, pp. 912-916.

Wang, J.; Li, M.; Shi, Z.; Li, N.; Gu, Z. (2004) Electrochemistry of DNA at single-wall carbon nanotubes, Electroanalysis, 16 (1-2), pp. 140-144.

Wang, J.; Liu, G.D.; Jan, M.R. (2004a) Ultrasensitive electrical biosensing of proteins and DNA: carbon nanotube derived amplification of the recognition and transduction events, Journal of the American Chemical Society, 126 (10), pp. 2010-3011.

Wang, J.; Musameh, M.; Lin, Y. (2003) Solubilization of carbon nanotubes by nafion: towards the preparation of amperometric biosensors. Journal of the American Chemical Society, 125, pp. 2408-2409.

Yu, X.; Chattopadhyay, D.; Galeska, I.; Papadimitrakopoulos, F. ; Rusling, J.F. (2003) Peroxidase activity of enzymes bound to the ends of single-wall carbon nanotube forest electrodes. Electrochemistry Communications, 5, (5), pp. 408-411.

Zhang, H. Hu, N. (2007) Assembly of myoglobin layer-by-layer films with poly(propyleneimine) dendrimer-stabilized gold nanoparticles and its application in electrochemical biosensing. Biosensensors and Bioelectronics 23, pp. 393-399.

Zhang, L.; Zhao, G.; Wei, X.; Yang, Z. (2004) Electroreduction of Oxygen by Myoglobin on Multi-walled Carbon Nanotube-Modified Glassy Carbon Electrode. Chem. Lett. 33, pp. 86-87.

Zhang, Z. Chouchane, S. Magliozzo, R. Rusling, S. (2002) Direct voltammetry and enzyme catalysis with M. Tuberculosis catalase-peroxidase, peroxidases and catalase in lipid films. Analytical Chemistry, 74, pp. 163.

Zhao, L.; Liu, H.; Hu, N. (2006) Electroactive films of heme protein-coated multiwalled carbon nanotubes. J. Colloid Interface Sci. 296, pp. 204-11.

Zhao, L.; Liu, H.; Hu, N. (2006a) Assembly of layer-by-layer films of heme proteins and single-walled carbon nanotubes: electrochemistry and electrocatalysis. Anal. Bioanal. Chem. 384, pp. 414-422. 


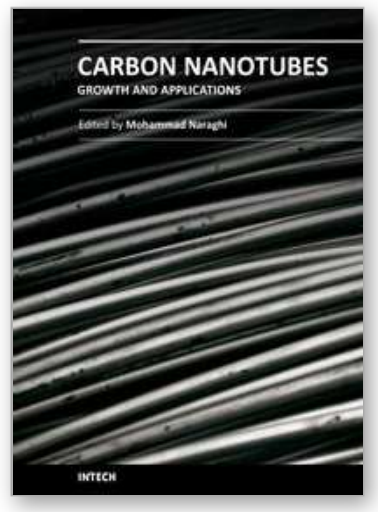

\section{Carbon Nanotubes - Growth and Applications}

Edited by Dr. Mohammad Naraghi

ISBN 978-953-307-566-2

Hard cover, 604 pages

Publisher InTech

Published online 09, August, 2011

Published in print edition August, 2011

Carbon Nanotubes are among the strongest, toughest, and most stiff materials found on earth. Moreover, they have remarkable electrical and thermal properties, which make them suitable for many applications including nanocomposites, electronics, and chemical detection devices. This book is the effort of many scientists and researchers all over the world to bring an anthology of recent developments in the field of nanotechnology and more specifically CNTs. In this book you will find:

- Recent developments in the growth of CNTs

- Methods to modify the surfaces of CNTs and decorate their surfaces for specific applications

- Applications of CNTs in biocomposites such as in orthopedic bone cement

- Application of CNTs as chemical sensors

- CNTs for fuelcells

- Health related issues when using CNTs

\section{How to reference}

In order to correctly reference this scholarly work, feel free to copy and paste the following:

M. Pacios, I. Martîn-Fernández, R. Villa, P. Godignon, M. Del Valle, J. Bartroli and M.J. Esplandiu (2011). Carbon Nanotubes as Suitable Electrochemical Platforms for Metalloprotein Sensors and Genosensors, Carbon Nanotubes - Growth and Applications, Dr. Mohammad Naraghi (Ed.), ISBN: 978-953-307-566-2, InTech, Available from: http://www.intechopen.com/books/carbon-nanotubes-growth-and-applications/carbonnanotubes-as-suitable-electrochemical-platforms-for-metalloprotein-sensors-and-genosensors

\section{INTECH}

open science | open minds

\section{InTech Europe}

University Campus STeP Ri

Slavka Krautzeka 83/A

51000 Rijeka, Croatia

Phone: +385 (51) 770447

Fax: +385 (51) 686166

www.intechopen.com

\section{InTech China}

Unit 405, Office Block, Hotel Equatorial Shanghai

No.65, Yan An Road (West), Shanghai, 200040, China

中国上海市延安西路65号上海国际贵都大饭店办公楼405单元

Phone: +86-21-62489820

Fax: +86-21-62489821 
(C) 2011 The Author(s). Licensee IntechOpen. This chapter is distributed under the terms of the Creative Commons Attribution-NonCommercialShareAlike-3.0 License, which permits use, distribution and reproduction for non-commercial purposes, provided the original is properly cited and derivative works building on this content are distributed under the same license. 